\title{
Mipomersen and other therapies for the treatment of severe familial hypercholesterolemia
}

\author{
This article was published in the following Dove Press journal: \\ Vascular Health and Risk Management \\ 27 November 2012 \\ Number of times this article has been viewed
}

\author{
Damon A Bell ${ }^{1-3}$ \\ Amanda J Hooper 1,2,4 \\ Gerald F Watts ${ }^{2,3}$ \\ John R Burnett ${ }^{1-4}$ \\ 'Department of Core Clinical \\ Pathology and Biochemistry, PathWest \\ Laboratory Medicine, ${ }^{2}$ School of \\ Medicine and Pharmacology, ${ }^{3}$ Lipid \\ Disorders Clinic, Department of \\ Internal Medicine, Royal Perth \\ Hospital, Perth, Western Australia, \\ Australia; ${ }^{4}$ School of Pathology and \\ Laboratory Medicine, University of \\ Western Australia, Perth, Western \\ Australia, Australia
}

\begin{abstract}
Familial hypercholesterolemia $(\mathrm{FH})$ is an autosomal dominant condition with a population prevalence of one in 300-500 (heterozygous) that is characterized by high levels of low-density lipoprotein (LDL) cholesterol, tendon xanthomata, and premature atherosclerosis and coronary heart disease (CHD). FH is caused mainly by mutations in the $L D L R$ gene. However, mutations in other genes including $A P O B$ and $P C S K 9$, can give rise to a similar phenotype. Homozygous $\mathrm{FH}$ with an estimated prevalence of one in a million is associated with severe hypercholesterolemia with accelerated atherosclerotic CHD in childhood and without treatment, death usually occurs before the age of 30 years. Current approaches for the treatment of homozygous FH include statin-based lipid-lowering therapies and LDL apheresis. Mipomersen is a second-generation antisense oligonucleotide (ASO) targeted to human apolipoprotein B (apoB)-100. This review provides an overview of the pathophysiology and current treatment options for familial hypercholesterolemia and describes novel therapeutic strategies focusing on mipomersen, an antisense apoB synthesis inhibitor. Mipomersen is distributed mainly to the liver where it silences apoB mRNA, thereby reducing hepatic apoB-100 and giving rise to reductions in plasma total cholesterol, LDL-cholesterol, and apoB concentrations in a doseand time-dependent manner. Mipomersen has been shown to decrease apoB, LDL-cholesterol and lipoprotein(a) in patients with heterozygous and homozygous FH on maximally tolerated lipid-lowering therapy. The short-term efficacy and safety of mipomersen has been established, however, injection site reactions are common and concern exists regarding the long-term potential for hepatic steatosis with this ASO. In summary, mipomersen given alone or in combination with standard lipid-lowering medications shows promise as an adjunct therapy in patients with homozygous or refractory heterozygous $\mathrm{FH}$ at high risk of atherosclerotic CHD, who are not at target or are intolerant of statins.
\end{abstract}

Keywords: antisense oligonucleotide, apolipoprotein B, familial hypercholesterolemia, LDLcholesterol, metabolism, mipomersen

\section{Introduction}

Familial hypercholesterolemia (FH) is the most common and severe form of monogenic hypercholesterolemia. ${ }^{1} \mathrm{FH}$ was the first genetic disease of lipid metabolism to be clinically and molecularly characterized. The main biochemical abnormality observed in FH is high levels of low-density lipoprotein (LDL)-cholesterol in plasma, due to reduced function of the LDL-receptor pathway, which removes LDL particles from the circulation into the liver. If untreated, patients develop premature coronary heart disease (CHD). The mean age of CHD is between 40 and 45 years in male and a decade later in female FH patients. Most people with FH are undiagnosed or only diagnosed after their first coronary event.
Correspondence: John Burnett Department of Core Clinical Pathology and Biochemistry, PathWest Laboratory Medicine, Royal Perth Hospital, Wellington Street, Perth, WA 6000 Australia

$\mathrm{Tel}+6 \mid 892243121$

$\mathrm{Fax}+61892241789$

Email john.burnett@health.wa.gov.au 
In the late 1930s, Müller was first to recognize that FH was an inherited disorder with related individuals exhibiting xanthomata, hypercholesterolemia, and premature CHD. ${ }^{2}$ In the 1960s, Khachadurian showed a gene-dosage effect, with homozygotes having a more severe phenotype than heterozygotes. ${ }^{3}$ A breakthrough occurred in the mid-1970s, when Brown et al elucidated the LDL-receptor pathway; ${ }^{4}$ Goldstein and Brown showed that defects in the LDL-receptor cause $\mathrm{FH},{ }^{5}$ a discovery that earned the authors the Nobel Prize in Physiology or Medicine in $1985 .{ }^{6}$

\section{Metabolic and molecular basis of $\mathbf{F H}$}

In the late 1970s, in vivo metabolic studies using radiolabeling showed in agreement with the underlying LDL receptor defect that patients with FH are characterized by a decreased clearance of LDL from the circulation and an increase in LDL synthesis, with changes in homozygotes being more marked than in heterozygotes, consistent with a gene dosage effect. ${ }^{7}$ These findings were confirmed by subsequent stable isotope studies demonstrating that the fractional catabolic rate of LDL-apoB (and, to a lesser extent, very low-density lipoprotein [VLDL]apoB and intermediate density lipoprotein [IDL]-apoB) is decreased in $\mathrm{FH}$, with the majority of studies also showing increased production of VLDL-, IDL-, and LDL-apoB, ${ }^{8-10}$ with the increased VLDL-apoB production rate being more pronounced in $\mathrm{FH}$ homozygotes than in heterozygotes. ${ }^{9}$

FH is an autosomal codominant inherited disorder of lipoprotein metabolism caused mainly by mutations in the LDL-receptor $(L D L R)$ gene. ${ }^{11,12}$ More than 1000 mutations causing FH have been reported; these span the entire $L D L R$ gene, which encodes the LDL-receptor (860 amino acids), and range from single nucleotide substitutions through to large structural rearrangements. ${ }^{13}$ While the majority of FH is caused by mutations in the $L D L R$, amino acid changes in apoB-100 also lead to a form of FH called familial liganddefective apoB-100. ${ }^{14}$ As well as having an important structural role in LDL, apoB-100 acts as a ligand for the LDL-receptor to facilitate clearance of LDL particles from plasma. Rare heterozygous gain-of-function mutations in PCSK 9 cause a severe form of FH by causing accelerated degradation of the LDL-receptor, while mutations in the adaptor protein LDLRAP1 can lead to a very rare form of autosomal recessive hypercholesterolemia. ${ }^{12}$

\section{Prevalence of FH}

Heterozygous FH is estimated to affect 1 in 300-500 individuals worldwide, but is more prevalent in certain populations,

where founder effects have led to one in 100 Afrikaners, ${ }^{15}$ one in 170 Christian Lebanese, ${ }^{16}$ and one in 270 Québécois ${ }^{17}$ carrying an FH-causing mutation. Homozygous or compound heterozygous $\mathrm{FH}$ has an estimated population prevalence of one in a million, with one in 30,000 Afrikaners, one in 100,000 Christian Lebanese, and one in 275,000 Québécois. ${ }^{15-17}$ The epidemiology, Neolithic origins, and modern distribution of FH has been the subject of a recent review. ${ }^{1}$

\section{Biochemical and clinical features of $\mathrm{FH}$}

Untreated heterozygous FH patients typically have plasma LDL-cholesterol concentrations ranging from 5-12 mmol/L. The hallmark physical finding in adult patients with $\mathrm{FH}$ is the presence of tendon xanthomas, characteristically seen in the extensor tendons of the hands and the Achilles tendons (Figure 1). Less common are xanthomas in the olecranon process and the tibial tuberosity. Corneal arcus and palpebral xanthomas may also be seen, but are less specific features of FH. About half of men and one third of women with FH experience a coronary event by the age of 60 years. ${ }^{18,19}$ Early atherosclerosis (observed as endothelial dysfunction and increased carotid intima-media thickness) can be seen in untreated FH children. ${ }^{20,21}$ The cumulative exposure in cholesterol-life years and the corresponding risk of developing CHD in FH is shown in Figure 2.

Homozygous FH, a more severe form of the disorder, is associated with severe hypercholesterolemia (typically plasma LDL-cholesterol ranging from $15-24 \mathrm{mmol} / \mathrm{L}$ ) with

A
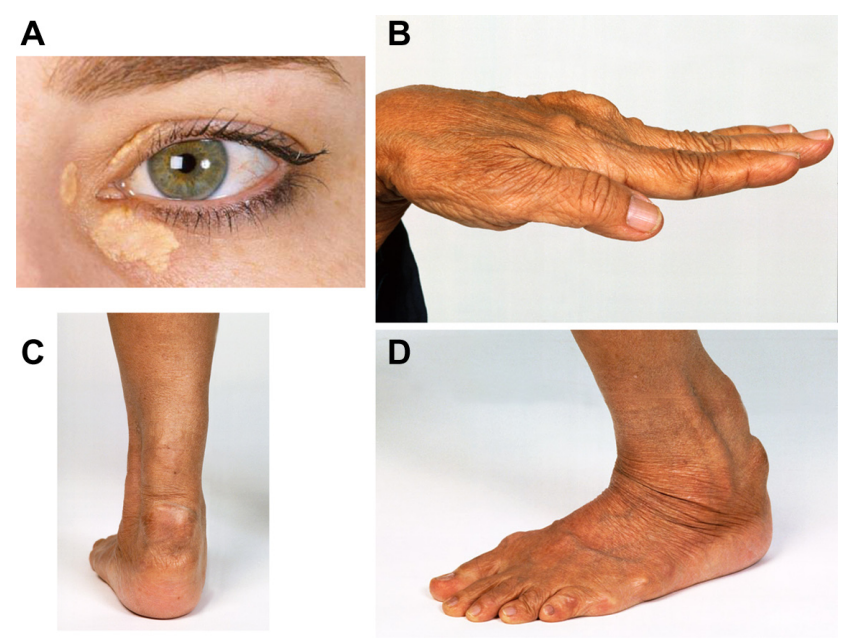

Figure I Discrete clinical manifestations of familial hypercholesterolemia. (A) Corneal arcus and xanthelasma; (B) extensor tendon xanthomas; (C and D) Achilles tendon xanthomas.

Note: Copyright (c) 2008, The Australian Association of Clinical Biochemists. Reproduced with permission from Burnett JR, Hooper AJ. Common and rare gene variants affecting plasma LDL cholesterol. Clin Biochem Rev. 2008;29(I): I I-26. ${ }^{68}$ 


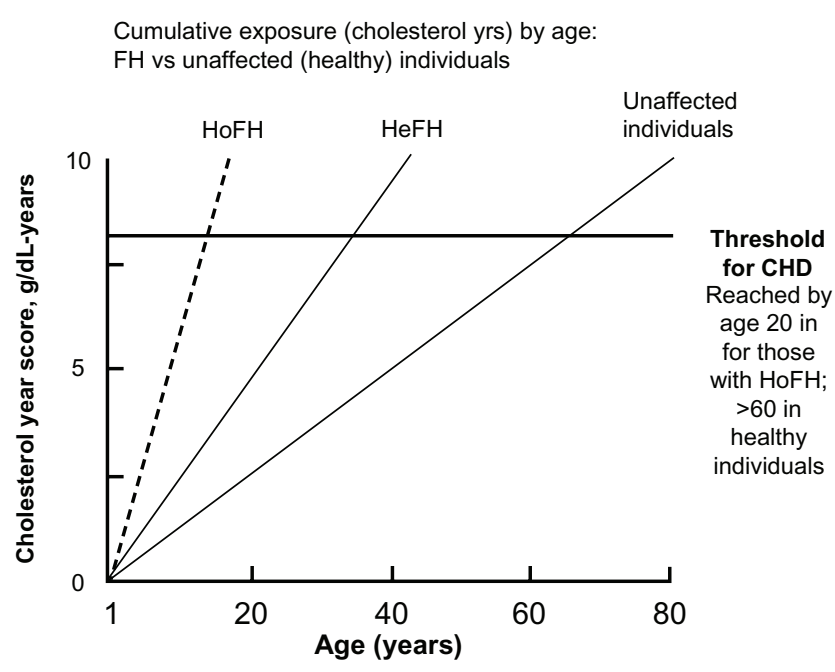

Figure 2 Cumulative LDL exposure (expressed as grams of cholesterol per year) over a lifetime in familial hypercholesterolemia patients $(\mathrm{HeFH}, \mathrm{HoFH})$ and normal individuals.

Note: Coronary heart disease occurs after a theoretical threshold of LDL exposure is exceeded, reached in early childhood in $\mathrm{HoFH}$ and early middle-age in $\mathrm{HeFH} .{ }^{27,69}$ Copyright (C) 2009, The American Society for Biochemistry and Molecular Biology. Adapted with permission from Horton JD, Cohen JC, Hobbs HH. PCSK9: a convertase that coordinates LDL catabolism. J Lipid Res. 2009;50 Suppl:SI72-SI77. ${ }^{69}$

Abbreviations: CHD, coronary heart disease; HeFH, heterozygous familia hypercholesterolemia; HoFH, homozygous familial hypercholesterolemia; LDL, lowdensity lipoprotein.

widespread accelerated atherosclerotic CHD as early as childhood and without treatment, death usually occurs before age $30 .{ }^{22}$ Patients with homozygous FH also exhibit aortic stenosis and atherosclerotic plaques involving the aortic root and supravalvular regions. ${ }^{23}$

\section{Diagnostic criteria for FH}

The clinical diagnosis of FH is based on a personal and family history, physical examination findings, and plasma cholesterol concentrations. However, there are no internationally agreed criteria for the phenotypic diagnosis of FH. Three diagnostic criteria currently in use are the Dutch Lipid Clinic Network criteria, the Simon Broome Register Group criteria, and the Make Early Diagnosis - Prevent Early Death (MED-PED) criteria. ${ }^{24-26}$ These criteria differ in their need for DNA testing and in their diagnostic effectiveness. There are also no internationally agreed phenotypic diagnostic criteria for homozygous $\mathrm{FH}$, although these have been recently reviewed by Raal and Santos, who describe that homozygous FH is generally based on the presence of xanthomata before the age of 10 years and an untreated LDL-cholesterol of $>13.0 \mathrm{mmol} / \mathrm{L}^{27}$

\section{Screening for FH}

FH meets the World Health Organization criteria for systematic screening. ${ }^{28}$ A variety of strategies have been proposed to screen for $\mathrm{FH}^{29}$ These include: (1) universal population screening; (2) opportunistic screening of patients consulting for unrelated reasons in primary care; (3) opportunistic screening of patients admitted to hospital with premature CHD; or (4) systematic screening of first-degree relatives of people diagnosed with $\mathrm{FH}$. We have recently shown that the community laboratory has the potential to assist with opportunistic FH screening. ${ }^{30}$

\section{Current approaches for the treatment of homozygous FH}

The cornerstone of treatment for FH is diet and lifestyle modifications and pharmacotherapy. 3-hydroxy3-methylglutaryl-coenzyme A reductase inhibitors (statins) are by far the most common and effective drugs with which to treat FH. However, statins require some residual LDL receptor function, thus they are not effective in receptor-negative homozygous FH. Statins decrease atherosclerotic CHD and have been shown to be cost-effective in the treatment of FH. Higher risk patients who require greater LDL-cholesterol and apoB reductions will require combination therapy to achieve therapeutic targets; especially ezetimibe, but also niacin, fibrates, and bile acid-binding resins. Therapeutic efficacy, safety, medication adherence, and compliance should be monitored closely. Effective lipid-lowering therapy has been demonstrated to reduce both mortality and major adverse cardiovascular events in individuals with homozygous $\mathrm{FH} .{ }^{31}$ However, trials confirming additional mortality and morbidity benefits over and above that of LDL-cholesterol lowering are required. Ezetimibe has been shown to effectively lower LDL-cholesterol when added to a statin, however, this did not lead to an improvement in carotid intima-media thickness over a 2-year follow-up period. ${ }^{32}$

LDL apheresis is a radical form of treatment for $\mathrm{FH}$ that entails the extracorporeal removal of apoB-containing lipoproteins from the circulation. LDL apheresis is indicated for patients with homozygous or compound heterozygous FH, as well as for patients with heterozygous FH with documented CHD who are refractory to pharmacotherapy. ${ }^{33,34}$ Importantly, LDL apheresis improves CHD outcomes, progression of atherosclerosis and aortic fibrosis, endothelial function, and coagulation and is supported by international guidelines. ${ }^{35}$ Homozygous patients who are not suitable for LDL apheresis should be considered for liver transplantation ${ }^{36}$ or enrolment in clinical trials of novel cholesterol-lowering treatments. It is difficult, if not impossible, to treat a patient with $\mathrm{FH}$ to the currently recommended LDL-cholesterol targets. ${ }^{37}$ Therefore, it is imperative that new therapeutic strategies be developed to lower LDL-cholesterol. 


\section{Novel strategies for the treatment of homozygous FH}

Several new therapeutic strategies to lower LDL-cholesterol have been developed for patients with homozygous FH. These include inhibitors of PCSK9, microsomal triglyceride transfer protein (MTTP), and cholesteryl ester transfer protein (CETP), as well as mipomersen, the focus of this review.

\section{PCSK9 inhibitors}

PCSK9, a serine protease that binds to the LDL-receptor promoting its degradation, is an important regulator of LDL metabolism. PCSK9 gain-of-function mutations are rare and cause $\mathrm{FH},{ }^{38}$ whereas more common loss-of-function mutations cause low LDL-cholesterol and atheroprotection. ${ }^{39,40}$ A compound heterozygote and a homozygote for PCSK 9 nonsense mutations each had a very low LDL-cholesterol at $\sim 0.4 \mathrm{mmol} / \mathrm{L} .{ }^{41,42}$

Statins are known to upregulate $P C S K 9$ potentially limiting their efficacy in reducing LDL-cholesterol levels. PCSK9 inhibitors, including antibodies, short-interfering RNA and antisense oligonucleotides are in development as a strategy for lowering plasma LDL-cholesterol and enhancing the LDL-cholesterol-lowering ability of statins. ${ }^{43-45}$ However, PCSK9 inhibitors require some residual LDL-receptor function, thus this approach is limited to heterozygous FH and those homozygotes with reduced, but not absent LDLreceptor function.

\section{MTTP inhibitors}

MTTP is a chaperone that facilitates apoB-containing lipoprotein assembly and secretion. ${ }^{46}$ MTTP plays a critical role in incorporating hepatic triglyceride with apoB leading to the formation of VLDL, which is subsequently the vehicle of lipid export from the liver.

Abetalipoproteinemia is an extreme form of MTTP inhibition characterized by marked hypocholesterolemia, absence of LDL-cholesterol and apoB, and low triglyceride concentrations. In addition, increased transaminases due to hepatic steatosis, acanthocytosis and fat-soluble vitamin deficiency are found. MTTP is a molecular target for therapies to decrease LDL-cholesterol, and apoB and MTTP inhibitors have potential as lipid-regulating and antiatherosclerotic agents. ${ }^{47,48}$

Lomitapide is a small-molecule MTTP inhibitor designed as an oral, once-daily treatment for homozygous FH. Lomitapide has been granted orphan drug status by the US Food and Drug Administration (FDA), and, in March 2012,
Aegerion Pharmaceuticals (Cambridge, MA) filed a New Drug Application (NDA) with the FDA and a Marketing Authorization Application with the European Medicines Agency (EMA) for lomitapide. A long-term safety and efficacy study for lomitapide in homozygous $\mathrm{FH}$ showed that the 23 patients who completed the 78-week trial achieved a 38\% reduction in LDL-cholesterol, and about half of apheresis patients either reduced or eliminated apheresis therapy. ${ }^{49}$ However, therapies for MTTP inhibition have also increased plasma transaminases and caused hepatic steatosis, ${ }^{50}$ the long-term significance of which is unknown.

\section{CETP inhibitors}

CETP transfers cholesteryl esters from high-density lipoprotein (HDL) to the apoB-containing lipoproteins. Individuals with CETP deficiency due to mutations in CETP have high levels of HDL-cholesterol. Inhibition of CETP is a target to increase HDL-cholesterol and potentially reduce atherosclerosis. ${ }^{51,52}$ CETP inhibition could potentially correct abnormalities in HDL-functionality in homozygous $\mathrm{FH}^{53}$

Torcetrapib, the first CETP inhibitor to be studied in a Phase III trial, was discontinued due to a number of off-target side effects, namely elevations in systolic blood pressure and increases in plasma aldosterone, sodium, and bicarbonate, and reductions in potassium, leading to increased mortality. ${ }^{54}$ Dalcetrapib, a structurally unrelated CETP "modulator," did not show major side effects; however, a lack of clinically meaningful benefit has meant that further testing of the drug has been halted. Anacetrapib added to statin therapy has been demonstrated to reduce LDL-cholesterol by a further $\sim 40 \%$ and increase HDLcholesterol by $\sim 140 \% .{ }^{55}$ The onus is now on anacetrapib to show that CETP inhibition can prevent coronary events, which is currently being investigated in the REVEAL trial. $^{56}$

\section{Mipomersen}

Mipomersen (Kynamro $^{\mathrm{TM}}$ [mipomersen sodium]; ISIS Pharmaceuticals, Carlsbad, CA), developed under the name ISIS 301012, is a second-generation antisense oligonucleotide (ASO), which is administered by subcutaneous injection in a formulation with $0.9 \%$ sodium chloride and targets apoB100 mRNA in the liver. Mipomersen has been granted orphan drug status by the FDA for the treatment of homozygous FH. In May 2012, an NDA for mipomersen was filed with the FDA by Genzyme Corporation (Cambridge, MA), who had previously filed mipomersen for marketing approval as a 
treatment for homozygous and severe heterozygous FH with the EMA in July 2011.

\section{Mode of action}

Mipomersen consists of a 20-mer 2'-O-methoxyethyl modified nucleotide complementary and specific to human apoB-100 mRNA. It distributes mainly to the liver, where it forms a duplex with the target mRNA, causing the mRNA to be cleaved by RNase $\mathrm{H}$ and therefore unable to be translated to apoB-100. Hepatic apoB mRNA silencing gives rise to reductions in hepatic apoB and plasma total cholesterol, LDL-cholesterol, and apoB concentrations in a dose- and time-dependent manner. ${ }^{57}$ The estimated median effective concentration $\left(\mathrm{EC}_{50}\right)$ in human liver is $81 \pm 122 \mu \mathrm{g} / \mathrm{g}$.

\section{Pharmacokinetics}

Pharmacokinetic studies have indicated that mipomersen has near complete systemic absorption and is rapidly and extensively distributed to tissues (volume of distribution in humans $48.3 \mathrm{~L} / \mathrm{kg}){ }^{58}$ Animal studies show that the highest levels of the oligonucleotide are found in liver and kidney. ${ }^{58}$ In plasma, greater than $85 \%$ of mipomersen is bound to plasma proteins. Animal studies suggest that plasma and liver concentrations of mipomersen are in equilibrium with a ratio of $1: 6000 .^{57}$

The half-life of mipomersen in humans has been calculated as approximately 30 days. ${ }^{57}$ Urinary excretion of the drug is minimal in the first 24 hours. Oligonucleotide metabolites, consisting of between seven and 14 nucleotides of the parent compound, can be detected in urine along with mipomersen. No potential pharmacokinetic interactions of mipomersen occur with coadministration of either simvastatin or ezetimibe, and nor does mipomersen inhibit cytochrome P450 enzyme activities. ${ }^{59}$

\section{Clinical efficacy}

Phase I trials showed that, in healthy individuals with mild dyslipidemia, mipomersen produces rapid and dosedependent prolonged reductions in serum apoB, total cholesterol and LDL-cholesterol, with the apoB and LDLcholesterol concentrations remaining below baseline for up to 3 months after the last dose. ${ }^{60}$

Subsequent Phase II and III trials have demonstrated that mipomersen is an effective lipid-lowering therapy in FH (Table 1). A Phase II trial in 44 heterozygous FH patients already taking conventional lipid-lowering therapy demonstrated that $300 \mathrm{mg}$ doses of mipomersen could safely, further reduce plasma apoB and LDL-cholesterol concentrations by one-third. ${ }^{61}$ Patients were randomized to receive subcutaneous mipomersen $(50,100,200$ or $300 \mathrm{mg})$ or placebo on days $1,4,8$ and 11 , followed by once-weekly injections to a total of 6 weeks. Significant reductions in apoB (23\% and 33\%) and LDL-cholesterol (21\% and 34\%) were observed in the $200 \mathrm{mg}$ and $300 \mathrm{mg}$ dose groups. While there was a trend towards reductions in lipoprotein(a) (Lp(a)), an important risk factor for coronary artery disease in $\mathrm{FH}$ that is highly heritable, ${ }^{62-64}$ these changes were not significant. Triglycerides and HDL-cholesterol levels were not significantly affected by mipomersen treatment. Four patients in the $300 \mathrm{mg}$ group continued out to 13 weeks in an extension study, showing reduced apoB and LDL-cholesterol, each by

Table I Effects of mipomersen on plasma apoB, LDL-cholesterol, triglyceride, HDL-cholesterol, and Lp(a) in FH

\begin{tabular}{|c|c|c|c|c|c|c|c|c|c|}
\hline \multirow[t]{2}{*}{ Study } & \multirow[t]{2}{*}{ Patient population } & \multirow[t]{2}{*}{ Duration } & \multirow{2}{*}{$\begin{array}{l}\text { Mipomersen dose } \\
\text { (mg/week) }\end{array}$} & \multirow{2}{*}{$\begin{array}{l}\text { Baseline LDL-C } \\
\text { (mmol/L) }\end{array}$} & \multicolumn{5}{|c|}{$\%$ change from baseline } \\
\hline & & & & & ApoB & LDL-C & TG & HDL-C & Lp(a) \\
\hline \multirow[t]{5}{*}{ Akdim et $\mathrm{al}^{61}$} & Heterozygous FH, & 6 weeks & 0 & $4.42 \pm 1.2$ & -1 & 0 & -16 & 8 & -3 \\
\hline & $n=44$ & & 50 & $5.35 \pm 2.0$ & -10 & -13 & 6 & -1 & -3 \\
\hline & & & 100 & $4.50 \pm 1.0$ & -8 & -11 & 6 & -3 & -15 \\
\hline & & & 200 & $4.24 \pm 0.8$ & $-23^{*}$ & $-2 I^{*}$ & $-23^{*}$ & -1 & -17 \\
\hline & & & 300 & $4.50 \pm 0.9$ & $-33^{*}$ & $-34 *$ & $-22 *$ & 6 & -24 \\
\hline \multirow[t]{2}{*}{ Raal et al ${ }^{65}$} & Homozygous FH, & 26 weeks & 0 & $10.4 \pm 3.7$ & -2.5 & -3.3 & 0.4 & 3.9 & -7.9 \\
\hline & $n=51$ & & 200 & $11.4 \pm 3.6$ & $-27^{*}$ & $-25^{*}$ & $-17^{*}$ & $15^{*}$ & $-3 I^{*}$ \\
\hline \multirow[t]{2}{*}{ Visser et $\mathrm{al}^{66}$} & Statin-intolerant patients, & 26 weeks & 0 & $6.3 \pm 1.7$ & -4.3 & -2.0 & 5.8 & -2.2 & 0 \\
\hline & including $\mathrm{FH}, \mathrm{n}=33$ & & 200 & $6.3 \pm 2.4$ & $-46^{*}$ & $-47 *$ & $-28^{*}$ & 8.1 & $-27^{*}$ \\
\hline Stein et $\mathrm{al}^{70}$ & Heterozygous FH, & 26 weeks & 0 & 3.70 & 7 & 5 & 0.9 & 5.2 & 0 \\
\hline (abstract) & $n=124$ & & 200 & 3.96 & $-26^{*}$ & $-28 *$ & $-14^{*}$ & 3.1 & $-2 I^{*}$ \\
\hline Tardif et $\mathrm{al}^{71}$ & Severe heterozygous FH, & 26 weeks & 0 & 6.44 & & 13 & & & \\
\hline (abstract) & $n=58$ & & 200 & 7.14 & & $-36 *$ & & & \\
\hline
\end{tabular}

Note: $* p<0.05$

Abbreviations: ApoB, apolipoprotein B; FH, familial hypercholesterolemia; HDL-C, high-density lipoprotein cholesterol; LDL-C, low-density lipoprotein cholesterol; Lp(a), lipoprotein (a); TG, triglyceride. 
$37 \%$ from baseline levels. These parameters remained below baseline for more than 3 months after the last dose.

The efficacy and safety of $200 \mathrm{mg} /$ week mipomersen has also been assessed in homozygous FH. ${ }^{65}$ Patients (mean age: 31 years) were all on stable maximum-tolerated lipid-lowering therapy, and over $80 \%$ had genetically confirmed homozygous or compound heterozygous FH. Of the 51 patients enrolled, all 17 assigned to the placebo group completed the 26-week treatment period, compared to 28 of the 34 assigned to mipomersen. The reasons given for withdrawal included injection site reactions $(n=2)$, rash, alanine aminotransferase (ALT) increase, noncompliance, and consent withdrawn. In the mipomersen group, the mean LDL-cholesterol reduced from $11.4 \mathrm{mmol} / \mathrm{L}$ at baseline to $8.4 \mathrm{mmol} / \mathrm{L}(-25 \%)$, with reductions near maximum at week 17 . However, there was variability in changes to LDL-cholesterol, which ranged between $2 \%$ to $-82 \%$, and was independent of baseline LDLcholesterol, age, race, or sex. Significant reductions in Lp(a) $(-31 \%)$ and triglyceride levels $(-17 \%)$, and an increase in HDL-cholesterol (15\%), were also observed.

Visser et al examined the effect of mipomersen in 33 statin-intolerant patients at high risk for cardiovascular disease. ${ }^{66}$ Over half of the patients were FH heterozygotes. Treatment with $200 \mathrm{mg} /$ week mipomersen for 26 weeks resulted in a $47 \%$ decrease in LDL-cholesterol, ranging from $-19 \%$ to $-77 \%$. This was predominantly the result of a reduction in small LDL particles $(-56 \% ; P=0.001 \mathrm{vs}$ placebo) rather than large LDL particles $(-4 \% ; P<0.017$ vs placebo). While triglycerides and $\mathrm{Lp}(\mathrm{a})$ levels were significantly reduced by mipomersen treatment, HDL-cholesterol and apoA-I concentrations did not change.

\section{Safety}

The majority of patients treated with mipomersen experience mild, transient injection site reactions, and about one-third experience flu-like symptoms. However, the focus of mipomersen's safety concerns has been on hepatic steatosis, as this was the major issue with suppression of VLDL production using MTTP inhibitors. Elevated plasma liver transaminases are common in patients on mipomersen therapy, and may be associated with the development of steatosis.

The impact of $200 \mathrm{mg} /$ week mipomersen on intrahepatic triglyceride content, assessed by proton magnetic resonance spectroscopy $\left({ }^{1} \mathrm{H}-\mathrm{MRS}\right)$, was studied in 21 patients with heterozygous $\mathrm{FH} .{ }^{67}$ Patients with a baseline liver fat greater than $5 \%$ were excluded from the trial. Liver fat content was assessed at baseline, where the mean intrahepatic triglyceride content was $1.2 \%$, and again at weeks 4 and 15 .
The most common adverse events were injection site reactions, which affected all patients in the mipomersen group (19\% of injections) compared to $73 \%$ of the placebo ( $9 \%$ of injections). Flu-like symptoms were observed in $70 \%$ of the mipomersen group and $18 \%$ of placebo. While no clinically significant increases in ALT were observed, the mean intrahepatic triglyceride content increased 0.8 percentage points in the mipomersen group at week 15, compared to a decrease of 0.1 percentage points in the placebo group $(P=0.051)$. In one patient, liver fat increased from $0.6 \%$ at baseline to $5.7 \%$ at week 15 , but this appeared to be reversible, decreasing to $2.5 \%$ at week 35 .

In a Phase III trial of homozygous FH patients, ${ }^{1} \mathrm{H}-\mathrm{MRS}$ quantification of liver fat content was performed at baseline and only remeasured in patients with increases in ALT greater than three times the upper reference limit. ${ }^{65}$ This corresponded to four patients $(12 \%)$ in the mipomersen group, and none in the placebo group. While two of these patients did not show an increase in hepatic steatosis, a third showed an increase in hepatic fat content from $9.6 \%$ to $24.8 \%$. Mipomersen treatment gave a strong lipid-lowering response in this patient, with a $75 \%$ reduction in LDL-cholesterol to $<1.8 \mathrm{mmol} / \mathrm{L}$ achieved by week 13 . The fourth patient had increased liver transaminases at baseline and again at week 17 where the protocol-defined stopping rule was met and dosing stopped.

In a trial of 33 statin-intolerant patients, the majority with $\mathrm{FH}, 81 \%$ of mipomersen-treated patients had increases in ALT above the upper limit of normal, compared to $25 \%$ of the placebo group. ${ }^{66}$ One-third of mipomersen-treated patients showed persistent elevations in liver transaminases greater than three times the upper reference limit. One patient in the mipomersen group met a stopping rule with liver transaminases elevated more than 10 times the upper reference limit in week 8 . However, the patient's intrahepatic triglyceride content was only $0.8 \%$ when measured in week 9 , and transaminases returned to normal within four weeks. Hepatic ${ }^{1} \mathrm{H}$-MRS was performed in all patients with elevated liver transaminases ( $>2$ times upper reference limit); hepatic steatosis was detected in 12 of 14 patients in the mipomersen group compared to 1 of 1 placebo-treated patients. The median intrahepatic triglyceride content was $24.4 \%$ in the mipomersen group, ranging from $0.8 \%$ to $47.3 \%$.

\section{Conclusion}

Mipomersen is an antisense apoB synthesis inhibitor that is currently in Phase III development for FH as a new treatment to lower apoB and LDL-cholesterol in patients at high risk of atherosclerotic CHD. Mipomersen is distributed mainly 
to the liver where it silences apoB mRNA, thereby reducing hepatic apoB-100 and giving rise to reductions in plasma total cholesterol, LDL-cholesterol, and apoB concentrations in a dose- and time-dependent manner. Unlike statins, mipomersen is not dependent on the LDL receptor for its mechanism of action.

Mipomersen has been shown to decrease apoB, LDLcholesterol and $\mathrm{Lp}(\mathrm{a})$ in patients with heterozygous and homozygous FH on maximally tolerated lipid-lowering therapy. Furthermore, mipomersen has the potential to reduce the frequency of LDL apheresis. The short-term efficacy and safety of mipomersen has been established, however, injection site reactions are a common occurrence and concern exists regarding the long-term potential for hepatic steatosis with this ASO and more detailed safety evaluations on human liver function are required.

The requirement for injection of mipomersen could present a barrier to patient uptake of this therapy. Further studies are required to develop an alternative delivery mode that would make this form of ASO available to a wider spectrum of patients who require to be treated to lower target levels of LDL-cholesterol either because current therapy is inadequate or that they cannot tolerate statins.

In summary, mipomersen given alone or in combination with standard lipid lowering medications shows promise as an adjunct therapy in patients with homozygous or refractory heterozygous $\mathrm{FH}$ at high risk of atherosclerotic CHD, who are not at target or are intolerant of statins. The long-term efficacy and safety and cost-effectiveness of mipomersen need to be demonstrated.

\section{Acknowledgment}

JRB is supported by a Practitioner Fellowship from the Royal Perth Hospital Medical Research Foundation.

\section{Disclosure}

The authors report no conflicts of interest in this work.

\section{References}

1. Liyanage KE, Burnett JR, Hooper AJ, van Bockxmeer FM. Familial hypercholesterolemia: epidemiology, Neolithic origins and modern geographic distribution. Crit Rev Clin Lab Sci. 2011;48(1):1-18.

2. Müller C. Xanthomata, hypercholesterolemia, angina pectoris. Acta Med Scand. 1938;89:75.

3. Khachadurian AK. The inheritance of essential familial hypercholesterolemia. Am J Med. 1964;37:402-407.

4. Brown MS, Kovanen PT, Goldstein JL. Regulation of plasma cholesterol by lipoprotein receptors. Science. 1981;212(4495):628-635.

5. Goldstein JL, Brown MS. The LDL receptor. Arterioscler Thromb Vasc Biol. 2009;29(4):431-438.

6. Brown MS, Goldstein JL. A receptor-mediated pathway for cholesterol homeostasis. Science. 1986;232(4746):34-47.
7. Bilheimer DW, Stone NJ, Grundy SM. Metabolic studies in familial hypercholesterolemia. Evidence for a gene-dosage effect in vivo. J Clin Invest. 1979;64(2):524-533.

8. Cummings MH, Watts GF, Umpleby M, Hennessy TR, Quiney JR, Sonksen PH. Increased hepatic secretion of very-low-densitylipoprotein apolipoprotein B-100 in heterozygous familial hypercholesterolaemia: a stable isotope study. Atherosclerosis. 1995; 113(1):79-89.

9. Millar JS, Maugeais C, Ikewaki K, et al. Complete deficiency of the low-density lipoprotein receptor is associated with increased apolipoprotein B-100 production. Arterioscler Thromb Vasc Biol. 2005;25(3): 560-565.

10. Tremblay AJ, Lamarche B, Ruel IL, et al. Increased production of VLDL apoB-100 in subjects with familial hypercholesterolemia carrying the same null LDL receptor gene mutation. J Lipid Res. 2004;45(5): 866-872.

11. Faiz F, Hooper AJ, van Bockxmeer FM. Molecular pathology of familial hypercholesterolemia, related dyslipidemias and therapies beyond the statins. Crit Rev Clin Lab Sci. 2012;49(1):1-17.

12. Soutar AK, Naoumova RP. Mechanisms of disease: genetic causes of familial hypercholesterolemia. Nat Clin Pract Cardiovasc Med. 2007; 4(4):214-225.

13. Leigh SE, Foster AH, Whittall RA, Hubbart CS, Humphries SE. Update and analysis of the University College London low density lipoprotein receptor familial hypercholesterolemia database. Ann Hum Genet. 2008;72(Pt 4):485-498.

14. Soria LF, Ludwig EH, Clarke HR, Vega GL, Grundy SM, McCarthy BJ. Association between a specific apolipoprotein B mutation and familial defective apolipoprotein B-100. Proc Natl Acad Sci U SA. 1989;86(2): $587-591$.

15. Seftel HC, Baker SG, Sandler MP, et al. A host of hypercholesterolaemic homozygotes in South Africa. BMJ. 1980;281(6241):633-636.

16. Fahed AC, Safa RM, Haddad FF, et al. Homozygous familial hypercholesterolemia in Lebanon: a genotype/phenotype correlation. Mol Genet Metab. 2011;102(2):181-188.

17. Moorjani S, Roy M, Gagne C, et al. Homozygous familial hypercholesterolemia among French Canadians in Quebec Province. Arteriosclerosis. 1989;9(2):211-216.

18. Slack J. Risks of ischaemic heart-disease in familial hyperlipoproteinaemic states. Lancet. 1969;2(7635):1380-1382.

19. Stone NJ, Levy RI, Fredrickson DS, Verter J. Coronary artery disease in 116 kindred with familial type II hyperlipoproteinemia. Circulation. 1974;49(3):476-488.

20. Tonstad S, Joakimsen O, Stensland-Bugge E, et al. Risk factors related to carotid intima-media thickness and plaque in children with familial hypercholesterolemia and control subjects. Arterioscler Thromb Vasc Biol. 1996;16(8):984-991.

21. Wiegman A, de Groot E, Hutten BA, et al. Arterial intima-media thickness in children heterozygous for familial hypercholesterolaemia. Lancet. 2004;363(9406):369-370.

22. Khachadurian AK, Uthman SM. Experiences with the homozygous cases of familial hypercholesterolemia. A report of 52 patients. Nutr Metab. 1973;15(1):132-140.

23. Summers RM, Andrasko-Bourgeois J, Feuerstein IM, et al. Evaluation of the aortic root by MRI: insights from patients with homozygous familial hypercholesterolemia. Circulation. 1998;98(6):509-518.

24. Risk of fatal coronary heart disease in familial hypercholesterolaemia. Scientific Steering Committee on behalf of the Simon Broome Register Group. BMJ. 1991;303(6807):893-896.

25. World Health Organization. Familial Hypercholesterolaemia (FH). Report of a second WHOT Consultation; Geneva; September 4, 1998. Geneva: World Health Organization Human Genetics Programme; 1999. Available from http://whqlibdoc.who.int/hq/1999/WHO_HGN_ FH_CONS_99.2.pdf. Accessed August 1, 2012.

26. Williams RR, Hunt SC, Schumacher MC, et al. Diagnosing heterozygous familial hypercholesterolemia using new practical criteria validated by molecular genetics. Am J Cardiol. 1993;72(2):171-176. 
27. Raal FJ, Santos RD. Homozygous familial hypercholesterolemia: Current perspectives on diagnosis and treatment. Atherosclerosis. 2012;223(2):262-268.

28. Wilson JM, Jungner G. Principles and Practice of Screening for Gisease. Geneva, Switzerland: World Health Organization; 1968.

29. Bender R, Bell DA, Hooper AJ, et al. Screening for familial hypercholesterolaemia. Pathology. 2012;44(2):122-128.

30. Bell DA, Hooper AJ, Bender R, et al. Opportunistic screening for familial hypercholesterolaemia via a community laboratory. Ann Clin Biochem. Epub September 21, 2012.

31. Raal FJ, Pilcher GJ, Panz VR, et al. Reduction in mortality in subjects with homozygous familial hypercholesterolemia associated with advances in lipid-lowering therapy. Circulation. 2011;124(20):2202-2207.

32. Kastelein JJ, Akdim F, Stroes ES, et al. Simvastatin with or without ezetimibe in familial hypercholesterolemia. $N$ Engl J Med. 2008; 358(14):1431-1443

33. Thompsen J, Thompson PD. A systematic review of LDL apheresis in the treatment of cardiovascular disease. Atherosclerosis. 2006;189(1): 31-38.

34. Thompson GR. Lipoprotein apheresis. Curr Opin Lipidol. 2010;21(6): 487-491.

35. Thompson GR, Catapano A, Saheb S, et al. Severe hypercholesterolaemia: therapeutic goals and eligibility criteria for LDL apheresis in Europe. Curr Opin Lipidol. 2010;21(6):492-498.

36. Moini M, Mistry P, Schilsky ML. Liver transplantation for inherited metabolic disorders of the liver. Curr Opin Organ Transplant. 2010; 15(3):269-276.

37. Pijlman AH, Huijgen R, Verhagen SN, et al. Evaluation of cholesterol lowering treatment of patients with familial hypercholesterolemia: a large cross-sectional study in The Netherlands. Atherosclerosis. 2010;209(1):189-194

38. Abifadel M, Varret M, Rabes JP, et al. Mutations in PCSK9 cause autosomal dominant hypercholesterolemia. Nat Genet. 2003;34(2): 154-156.

39. Benn M, Nordestgaard BG, Grande P, Schnohr P, Tybjaerg-Hansen A. PCSK9 R46L, low-density lipoprotein cholesterol levels, and risk of ischemic heart disease: 3 independent studies and meta-analyses. J Am Coll Cardiol. 2010;55(25):2833-2842.

40. Cohen JC, Boerwinkle E, Mosley TH Jr, Hobbs HH. Sequence variations in PCSK9, low LDL, and protection against coronary heart disease. N Engl J Med. 2006;354(12):1264-1272.

41. Hooper AJ, Marais AD, Tanyanyiwa DM, Burnett JR. The C679X mutation in PCSK9 is present and lowers blood cholesterol in a Southern African population. Atherosclerosis. 2007;193(2):445-448.

42. Zhao Z, Tuakli-Wosornu Y, Lagace TA, et al. Molecular characterization of loss-of-function mutations in PCSK9 and identification of a compound heterozygote. Am J Hum Genet. 2006;79(3):514-523.

43. McKenney JM, Koren MJ, Kereiakes DJ, Hanotin C, Ferrand AC, Stein EA. Safety and efficacy of a monoclonal antibody to proprotein convertase subtilisin/kexin type 9 serine protease, SAR236553/ REGN727, in patients with primary hypercholesterolemia receiving ongoing stable atorvastatin therapy. J Am Coll Cardiol. 2012;59(25): 2344-2353.

44. Stein EA, Gipe D, Bergeron J, et al. Effect of a monoclonal antibody to PCSK9, REGN727/SAR236553, to reduce low-density lipoprotein cholesterol in patients with heterozygous familial hypercholesterolaemia on stable statin dose with or without ezetimibe therapy: a phase 2 randomised controlled trial. Lancet. 2012;380:29-36.

45. Stein EA, Mellis S, Yancopoulos GD, et al. Effect of a monoclonal antibody to PCSK9 on LDL cholesterol. N Engl J Med. 2012;366(12): 1108-1118.

46. Hussain MM, Iqbal J, Anwar K, Rava P, Dai K. Microsomal triglyceride transfer protein: a multifunctional protein. Front Biosci. 2003; 8:500-506.

47. Burnett JR, Watts GF. MTP inhibition as a treatment for dyslipidaemias: time to deliver or empty promises? Expert Opin Ther Targets. 2007; 11(2):181-189.
48. Hussain MM, Bakillah A. New approaches to target microsomal triglyceride transfer protein. Curr Opin Lipidol. 2008;19(6):572-578.

49. Aegerion Pharmaceuticals: We are Bullish on the Lomitapide Story. June 8, 2012. Available from: http://seekingalpha.com/article/645951aegerion-pharmaceuticals-we-are-bullish-on-the-lomitapide-story. Accessed October 12, 2012.

50. Cuchel M, Bloedon LT, Szapary PO, et al. Inhibition of microsomal triglyceride transfer protein in familial hypercholesterolemia. $N$ Engl J Med. 2007;356(2):148-156

51. Hooper AJ, Burnett JR. Dalcetrapib, a cholesteryl ester transfer protein modulator. Expert Opin Invest Drugs. 2012;21(9):1427-1432.

52. Hooper AJ, Burnett JR. Anacetrapib, a cholesteryl ester transfer protein inhibitor. Expert Opin Invest Drugs. 2012;21(1):103-109.

53. Guerin M. Reverse cholesterol transport in familial hypercholesterolemia. Curr Opin Lipidol. 2012;23(4):377-385.

54. Barter PJ, Caulfield M, Eriksson M, et al. Effects of torcetrapib in patients at high risk for coronary events. $N$ Engl J Med. 2007;357(21): 2109-2122.

55. Cannon CP, Shah S, Dansky HM, et al. Safety of anacetrapib in patients with or at high risk for coronary heart disease. $N$ Engl J Med. 2010;363(25):2406-2415.

56. REVEAL: Randomized EValuation of the Effects of Anacetrapib Through Lipid-modification. August 2012. Available from: http://clinicaltrials.gov/ ct2/show/NCT01252953. Accessed October 12, 2012.

57. Yu RZ, Lemonidis KM, Graham MJ, et al. Cross-species comparison of in vivo $\mathrm{PK} / \mathrm{PD}$ relationships for second-generation antisense oligonucleotides targeting apolipoprotein B-100. Biochem Pharmacol. 2009; 77(5):910-919.

58. Yu RZ, Kim TW, Hong A, Watanabe TA, Gaus HJ, Geary RS. Cross-species pharmacokinetic comparison from mouse to man of a second-generation antisense oligonucleotide, ISIS 301012, targeting human apolipoprotein B-100. Drug Metab Dispos. 2007;35(3): 460-468.

59. Yu RZ, Geary RS, Flaim JD, et al. Lack of pharmacokinetic interaction of mipomersen sodium (ISIS 301012), a 2'-O-methoxyethyl modified antisense oligonucleotide targeting apolipoprotein B-100 messenger RNA, with simvastatin and ezetimibe. Clin Pharmacokinet. 2009;48(1):39-50.

60. Kastelein JJ, Wedel MK, Baker BF, et al. Potent reduction of apolipoprotein B and low-density lipoprotein cholesterol by short-term administration of an antisense inhibitor of apolipoprotein B. Circulation. 2006;114(16):1729-1735.

61. Akdim F, Visser ME, Tribble DL, et al. Effect of mipomersen, an apolipoprotein B synthesis inhibitor, on low-density lipoprotein cholesterol in patients with familial hypercholesterolemia. Am J Cardiol. 2010;105(10):1413-1419.

62. Clarke R, Peden JF, Hopewell JC, et al. Genetic variants associated with Lp(a) lipoprotein level and coronary disease. $N$ Engl J Med. 2009;361(26):2518-2528

63. Erqou S, Kaptoge S, Perry PL, et al. Lipoprotein(a) concentration and the risk of coronary heart disease, stroke, and nonvascular mortality. JAMA. 2009;302(4):412-423.

64. Nenseter MS, Lindvig HW, Ueland T, et al. Lipoprotein(a) levels in coronary heart disease-susceptible and -resistant patients with familial hypercholesterolemia. Atherosclerosis. 2011;216(2):426-432.

65. Raal FJ, Santos RD, Blom DJ, et al. Mipomersen, an apolipoprotein B synthesis inhibitor, for lowering of LDL cholesterol concentrations in patients with homozygous familial hypercholesterolaemia: a randomised, double-blind, placebo-controlled trial. Lancet. 2010;375(9719):998-1006.

66. Visser ME, Wagener G, Baker BF, et al. Mipomersen, an apolipoprotein B synthesis inhibitor, lowers low-density lipoprotein cholesterol in high-risk statin-intolerant patients: a randomized, double-blind, placebo-controlled trial. Eur Heart J. 2012;33(9): 1142-1149.

67. Visser ME, Akdim F, Tribble DL, et al. Effect of apolipoprotein-B synthesis inhibition on liver triglyceride content in patients with familial hypercholesterolemia. J Lipid Res. 2010;51(5):1057-1062. 
68. Burnett JR, Hooper AJ. Common and rare gene variants affecting plasma LDL cholesterol. Clin Biochem Rev. 2008;29(1):11-26.

69. Horton JD, Cohen JC, Hobbs HH. PCSK9: a convertase that coordinates LDL catabolism. J Lipid Res. 2009;50 Suppl:S172-S177.

70. Stein EA, Dufour R, Gagne C, et al. A randomized, double-blind, placebo-controlled study to assess efficacy and safety of mipomersen as add-on therapy in heterozygous familial hypercholesterolemia patients with coronary artery disease. Eur Heart J. 2010;31:898.
71. Tardif JC, McGowan M, Ceska R, et al. Apolipoprotein B synthesis inhibition by mipomersen reduces low-density lipoprotein cholesterol when added to maximally tolerated lipid-lowering medication in patients with severe heterozygous hypercholesterolemia. J Am Coll Cardiol. 2011;57(14):E492.

\section{Publish your work in this journal}

Vascular Health and Risk Management is an international, peerreviewed journal of therapeutics and risk management, focusing on concise rapid reporting of clinical studies on the processes involved in the maintenance of vascular health; the monitoring, prevention and treatment of vascular disease and its sequelae; and the involvement of metabolic disorders, particularly diabetes. This journal is indexed on PubMed Central and MedLine. The manuscript management system is completely online and includes a very quick and fair peer-review system, which is all easy to use. Visit http://www.dovepress.com/ testimonials.php to read real quotes from published authors.

Submit your manuscript here: http://www.dovepress.com/vascular-health-and-risk-management-journal 